\title{
The effects of spatial, temporal, and control variables on the free-recall serial position curve of retardates and equal-MA normals*
}

\author{
HERMAN H. SPITZ $\dagger$, JOHN J. WINTERS, JR., SHIRLEY J. JOHNSON, and JANICE G. CARROLL \\ E. R. Johnstone Training and Research Center, Bordentown, New Jersey 08505
}

\begin{abstract}
In Experiment I seven pictures were sequentially illuminated at a 3 -sec rate through seven translucent windows. A different window provided the starting point for each of seven tests. Retarded and normal Ss of equal MA produced equivalent free recall and reliable recency effects. Although groups did not differ significantly at any portion of the curve, only the normals produced a significant primacy effect. The spatial end anchors produced no significant primacy or recency effects. In Experiment II total presentation time remained the same but the pictures were presented at a 1-sec rate. Variations in elapsed time and number of presentations produced a negative primacy effect. a result attributed to the prevention of selective rehearsal and the resultant interaction of trace decay and order of recall. Superior recall by the normals, particularly in the recency portion of the curve, was attributed to group differences in order of recall strategies.
\end{abstract}

When averaged over several trials, the serial position curve in free recall is -as it is in serial recall-a bow-shaped curve. In free recall the curve is generally $\mathbf{J}$ shaped, while in serial anticipation recall it is an inverted J-shaped curve, at least when list length is sufficiently long (Jahnke, 1965). The ubiquity of this effect has elicited a number of explanations, none definitive. One popular explanation for the $\mathrm{J}$-shaped free-recall function has been based on stages of memory. That is, the last items of a list are recalled best (recency effect) because they are in short-term store and readily available, while the first items are recalled next best (primacy effect) primarily because they have been rehearsed more frequently than intermediate items and, therefore, are more firmly held in long-term store (Atkinson \& Shiffrin, 1968; Rundus, 1971; Waugh \& Norman, 1965). Selective cumulative rehearsal as an explanation of the primacy effect in free recall has a rather long history (Welch \& Burnett, 1924).

Alternative explanations have included the suggestion that it is the type of processing, not merely the number of repetitions, which plays a crucial role in producing the serial position curve (e.g., Craik \& Watkins, 1973). Similarly, both the primacy and recency effects have been attributed to the order in which the Ss choose to learn the items, this order usually depending upon such anchor points as the first and last items of the list (e.g., Feigenbaum \& Simon, 1962; Jensen, 1962). There are, of course, still other explanations.

*For cooperating in these experiments, we thank the students at Johnstone and the students at Roebling School No. 5 and their Principal, Samuel Kaltovich. We thank Mary Anne Brzoska, who painted the pictures, and David L. Hoats for the electronic programming of the apparatus.

thequests for reprints should be sent to Herman $H$. Spitz, E. R. Johnstone Training and Research Center, Bordentown, New Jersey 08505 .
The fact that different groups perform differently at different portions of the curve makes determination of the source of the serial position curve of more than academic interest. If the sources of the curve's shape can be determined, a deficiency in a particular portion of the curve can be ascribed to a deficiency in a particular function or functions. For example, Ellis (1970) has suggested that, because mentally retarded Ss do not differ from nonretarded Ss of equal CA on the recency portion of the curve, differences in the remaining portions most likely are due to the inadequate rehearsal strategies of the retarded, a suggestion that has received considerable support (Belmont \& Butterfield, 1971; Brown, Campione, Bray, \& Wilcox, 1973). On the other hand, Bray (1973), using a slightly different procedure, did find a strong primacy effect for retarded Ss, which he ascribed to rehearsal strategy. However, a primacy effect remained even after Ss were apparently prevented from rehearsing. Kellas, Ashcraft, and Johnson (1973) also found a clear primacy effect, along with evidence that half of their mildly retarded adolescent Ss were rehearsing. Even Ss who apparently did not cumulatively rehearse produced the bowed serial position curve.

The present study was designed (a) to examine the differential effects of spatial and temporal end anchors on the serial position curve, (b) to determine whether forced overt rehearsal (repetition) and differential presentation exposures alter the typical J-shaped function of the free-recall curve, and (c) to compare retarded and equal-MA normal children on these conditions with the hope of throwing some explanatory light on any performance differences that might be found. Experiment I was designed primarily to investigate Purposes a and c; Experiment II was designed to investigate Purposes $\mathrm{b}$ and $\mathrm{c}$. 


\section{EXPERIMENT I}

A number of studies have presented the items in a spatial array. That is, items were presented one at a time, from left to right, after which one of the positions was probed (Atkinson \& Shiffrin, 1968; Bray, 1973); or a duplicate of one of the items was presented above the array and the $\mathrm{S}$ was required to indicate the position where that item had been presented (Ellis, 1970). Under those conditions, not only temporal anchors (first and last items) but also spatial anchors (items at either end of the array) are available to the S. In order to determine whether or not spatial anchors contribute to the serial position effect, we will present seven different sets of pictures and start each set at one of the seven positions. If spatial anchors are used to any extent, then the items presented at the ends of the array will be remembered best, no matter when in the temporal sequence they are presented.

\section{Method}

Subjects. The group of institutionalized retarded Ss, residents of the Johnstone Center, consisted of six girls and eight boys $(\overline{\mathrm{CA}}=16.13$ years, $\mathrm{SD}=.70 ; \overline{\mathrm{I}}=60, \mathrm{SD}=7 ; \overline{\mathrm{M}} \overline{\mathrm{A}}=9.56$ years, $\mathrm{SD}=1.13$ ). The nonretarded group, from a neighboring public school, consisted of seven girls and seven boys $(\overline{\mathrm{C}} \overline{\mathrm{A}}=8.68$ years, $\mathrm{SD}=.29 ; \overline{\mathrm{IQ}}=109, \mathrm{SD}=9 ; \overline{\mathrm{MA}}=9.51$ years, $\mathrm{SD}=.94)$. The mean IQ of the retarded group was based on individually administered Wechsler Intelligence Scales. The mean IQ of the normal group was based on individually administered Slosson Intelligence Tests available on 12 of the 14 Ss. Members of the retarded group were free of gross motor or neurological impairment.

Materials and Procedure. Chromatic slides were made of 49 watercolor paintings of common objects. In order to insure that all pictures could be identified, prior to the main experiment the 49 pictures were back-projected in a prearranged order onto a screen at a 5-sec rate. In those rare instances where an object was not recognized, the $S$ was told what it was. Immediately after the last slide, Ss were requested to recall as many pictures as they could. This was required in order to determine if the preliminary identification task had any undue residual effect on the main experiment. Subsequent analy sis of this recall ind icated that it did not. That is, the ratio of recall in the main experiment of those pictures recalled in the preliminary task was not reliably greater than the ratio of recall of the remaining pictures.

For the main experiment, the 49 slides were divided into seven sets, and the 7 slides of each set were then placed into seven different orders in a randomized balanced Latin-Square design. Thus, each picture was in each position an equal number of times, but no $\mathrm{S}$ saw the same picture more than once. The display panel was a horizontal array of seven round windows, $22 \mathrm{~mm}$ apart, each $47 \mathrm{~mm}$ in diam. In front of the windows was a sheet of Plexiglas (1.59-mm-thick gray Plexiglas acrylic plastic sheet, Rohm and Haas, No. 2074) which was dark enough to occlude the slides, except when a 7.5-W bulb at the rear of a window was activated and illuminated the picture. A tube around each bulb prevented the escape of ambient light.

Each $\mathrm{S}$ viewed seven different sets of pictures, with each set having a different start and end position as follows: $3-2,6-5,2-1$, $4-3,1-7,7-6$, and $5-4$ (with " 1 " designating the window to the $S$ 's far left). Each slide was illuminated for $3 \mathrm{sec}$, followed immediately by illumination of the next slide. The sequence always went from the S's left to right, except when going from

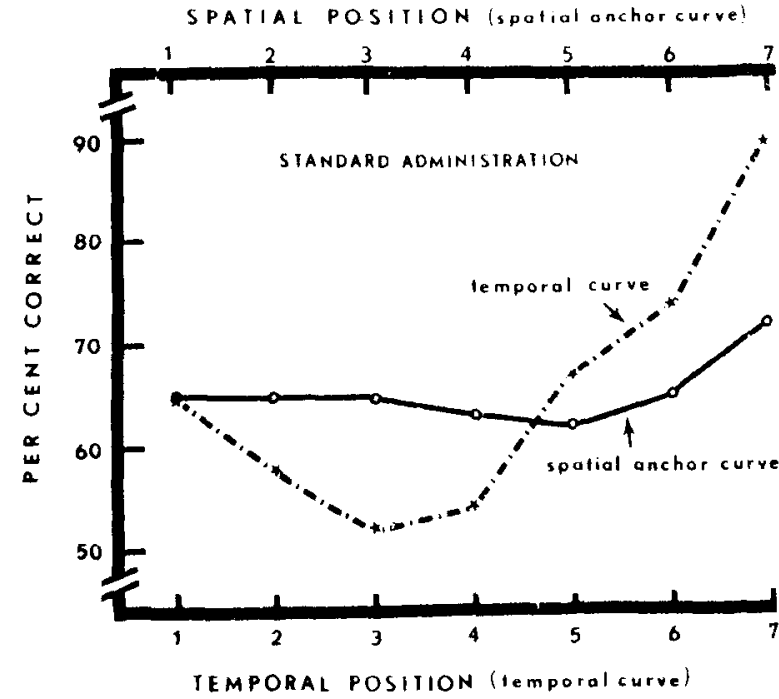

Fig. 1. Temporal curve and spatial anchor curve of institutionalized adolescent retarded group, Experiment 1 . Source of curves explained in text.

the seventh to the first slide. Each sequence was S activated by means of a switch in front and to the right of the display panel. The $S$ sat approximately $.91 \mathrm{~m}$ from the display.

Prior to the first presentation only, the first sequence (3-2) was activated without slides in order to demonstrate the nature of the sequence. Then a set of seven slides was inserted and $S$ was told that these would be the same pictures he had just seen on the screen and that he was to name the picture once as each slide was illuminated. Prior to each sequence, the $\mathrm{E}$ pointed to the first window of that sequence and showed how the sequence would cycle through and where it would end. At the end of each sequence, a single muted door chime signaled the $S$ to free recall.

\section{Results}

The temporal serial position curve for each group is shown in Figs. 1 and 2. Since 14 Ss were presented with

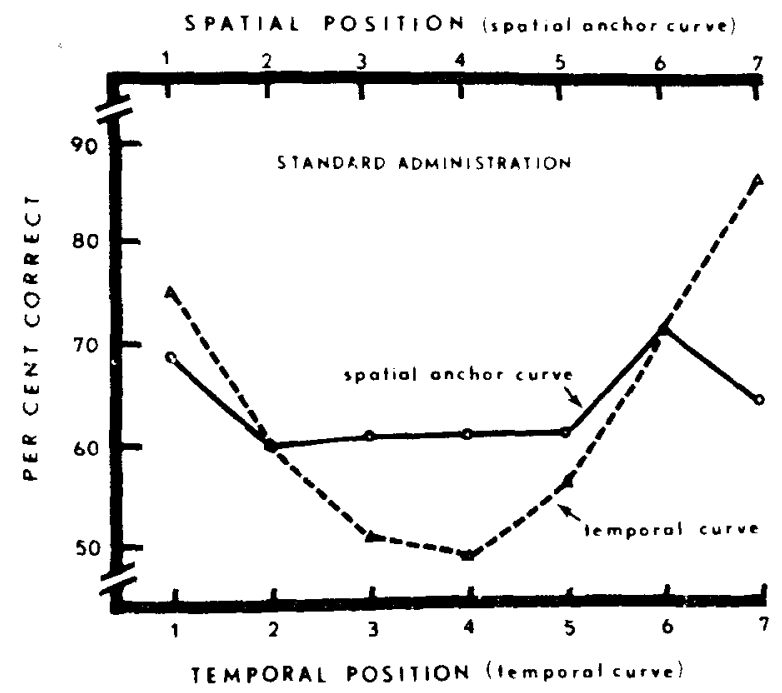

Fig. 2. Temporal curve and spatial anchor curve of equal-MA normal group, Experiment 1 . 
seven sets of seven pictures, each data point represents the average score of 98 observations. For the temporal curve, the data point plotted at Position 1 on the abscissa represents the average recall for the first item presented, regardless of its position in the spatial array, the point at Position 2 represents recall on the second item presented, and so on. Both groups produced the typical J-shaped curve. A 2 by 7 (groups by temporal positions) ANOVA indicated that temporal position was a significant variable $[F(6,156)=11.54, \mathrm{p}<.001]$, but neither the main effect of groups nor the interaction were significant. The retarded group recalled an average of 4.59 pictures; the normals recalled an average of 4.49 pictures.

Although both primacy and recency effects were significant for the normals, only the recency effect was reliable for the retarded group. The Newman-Keuls procedure indicated that for retardates Temporal Position 7 was reliably higher than Positions $1,2,3$, and 4 , and Position 6 was reliably higher than Position 3 , but no other differences were statistically reliable. For the normals, Position 7 was reliably higher than Positions 2 , 3 , 4, and 5, Position 6 was reliably higher than Position 4, but, in addition, Position 1 was reliably higher than Positions 3 and 4 ( $p$ at least $<.05$ ).

The spatial anchor curves are also shown in Figs. 1 and 2. For the spatial anchor curve, the data point plotted at Position 1 on the abscissa represents the average recall for the items presented in the far left window, regardless of when in the list of seven items it was presented, the point at Position 2 represents recall for items presented in the second window, and so on. Neither group showed a reliable end anchor effect. A 2 by 7 (groups by spatial position) ANOVA for these curves produced no significant main effects or interaction. For neither group was any point on the spatial anchor curve reliably different from any other point.

To measure recall strategies, the percentage of times Ss started recall from the last presented item was plotted. Figure 3 shows that this was the most prominent strategy for both groups. Figure 4 shows that, in both $\mathrm{S}$ groups, only a small percentage of times did Ss begin their recall with the first item presented. There were no statistically significant differences between $S$ groups on either of these curves.

\section{Discussion}

In regard to the temporal serial position curve, the finding that the retarded group did not show a reliable primacy effect is congruent with results reported by Ellis (1970). Since the use of spatial anchors was ruled out as an important explanatory variable, his hypothesis that retardates have a deficient rehearsal mechanism remains tenable. However, although the normals had a significant primacy effect and the retardates did not, the two groups did not differ significantly on Item 1 . In fact, the two groups did not differ in total recall, primarily
STANDARD ADMINISTRATION

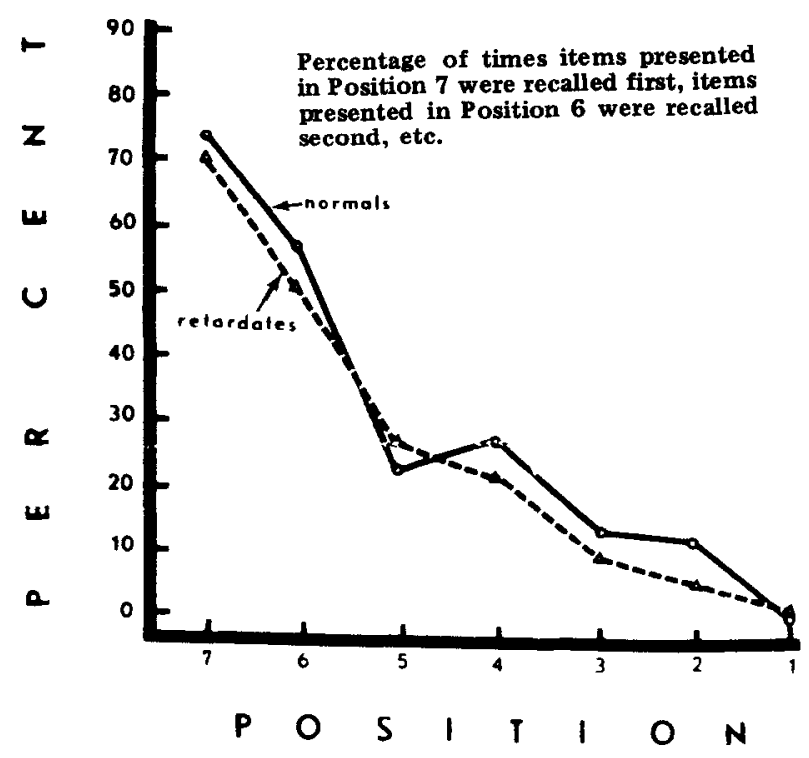

Fig. 3. Order of recall curves for the recency items, Experiment I. Percentage was derived by dividing the number of times the seventh item was recalled first by the total number of times the seventh item was recalled, etc.

because the retarded group's relatively good performance on Temporal Positions 4 and 5 compensated for their relatively poor performance on Temporal Position 1. Ellis, of course, compared retarded Ss with normals of equal CA, while our two groups were of approximately equal MA.

It is of incidental interest to note that larger recency than primacy effects did not develop until after Trial 1 , confirming Hasher's (1973) similar findings.

\section{STANDARD ADMINISTRAIION}

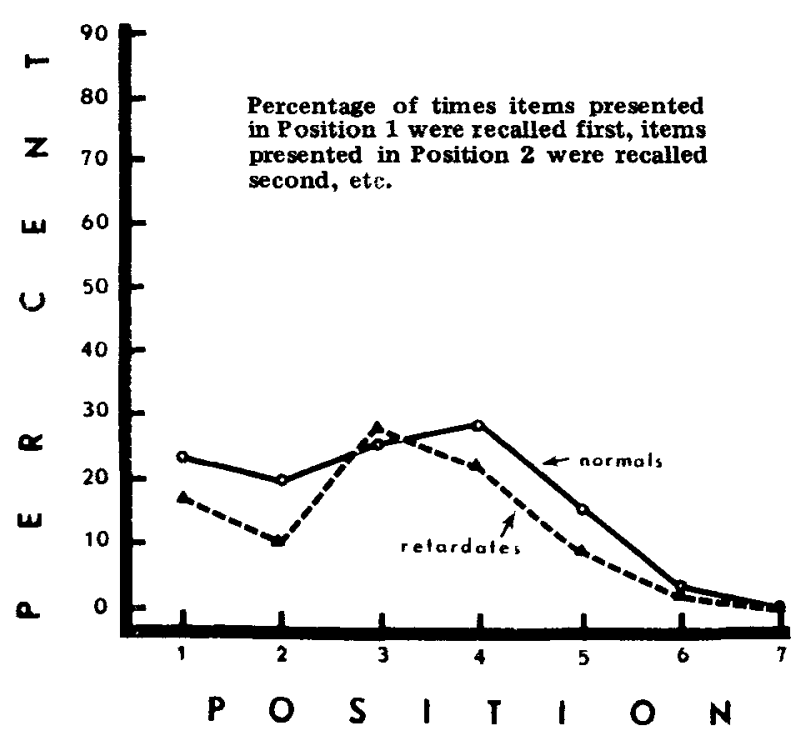

Fig. 4. Order of recall curves for the primacy items, Experiment I. 


\section{EXPER IMENT II}

Having established that these $\mathrm{S}$ groups produce the bow-shaped serial position curve, it was possible to manipulate certain input variables in an attempt to alter the shape of the curve. Since rehearsal is said to be a major source of the primacy effect, in Experiment II rehearsal was manipulated, but in a manner slightly different than that used in previous studies (Fischler, Rundus, \& Atkinson, 1970). That is, total time was kept the same as in Experiment I but, in an effort to eliminate the "bowing" of the curve, Ss were forced to overtly repeat the names of the pictures in the center of the list more frequently than the pictures presented at the beginning and end of the list. In addition, amount of elapsed time was manipulated. The final offset of Item 1 was $18 \mathrm{sec}$ and of Item 2 was $12 \mathrm{sec}$ prior to free recall, presumably putting them beyond primary memory; final offsets of Items 3-7 were within $4 \mathrm{sec}$ of free recall, presumably putting them in primary memory and, for the last one or two items, sensory store.

\section{Method}

Subjects. Students who had not participated in Experiment I were drawn from the same schools. The retarded group consisted of seven boys and seven girls $(\overline{\mathrm{C}} \overline{\mathrm{A}}=15.46$ years, $\mathrm{SD}=.71$; $\overline{\mathrm{IQ}}=62, \mathrm{SD}=7 ; \overline{\mathrm{MA}}=9.49$ years, $\mathrm{SD}=1.20$ ). The nonretarded group consisted of seven girls and seven boys $(\overline{\mathrm{C}} \overline{\mathrm{A}}=8.62$ years, $\mathrm{SD}=.44 ; \overline{\mathrm{IQ}}=112, \mathrm{SD}=10 ; \overline{\mathrm{MA}}=9.66$ years, $\mathrm{SD}=.80)$. The mean IQ of the retarded group was based on individually administered Wechsler Intelligence Scales, and the mean IQ of the normals was based on individually administered Slosson Intelligence Tests available on 13 of the $14 \mathrm{Ss}$. Members of the retarded group were free from gross motor or neurological impairment.

Materials and Procedure. The same apparatus and slides were used as in Experiment $I$. The preliminary identification and free recall of the 49 slides was again administered and again subsequent analysis indicated that free recall of the 49 slides did not show a residual effect on recall in the main experiment.

The same seven sets of slides were used as in Experiment I, but each picture was illuminated for only $1 \mathrm{sec}$ at a time. In order to prevent covert rehearsal and control cumulative overt rehearsal, Ss were required to say the name of each picture each time the slide was illuminated. The order of presentation was as follows, with the number "1" representing the first window (to the S's left) and the number " 7 " representing the final window (to the S's right): 1, 2, 1, 2, 3, 2, 3, 4, 2, 3, 4, 5, 3, 4, 5, 6, 3, 4, $5,6,7$. In this arrangement, Slide 7 was illuminated once for $1 \mathrm{sec}$, Slides 1 and 6 were each illuminated twice for a total of 2 sec each, Slide 5 was illuminated three times for a total of $3 \mathrm{sec}$, and so on (see top abscissa of Fig. 5). The final off set of Slide 1 occurred $18 \mathrm{sec}$ prior to the recall chime, while the final off set of Slide 2 occurred $12 \mathrm{sec}$ prior to recall. Final off sets of Slides 3-7 occurred 4,3,2,1, and 0 sec, respectively, prior to the recall chime.

After the instructions, which were the same as in Experiment I and included a demonstration of the sequence without slides inserted, the first set of seven slides was placed in the apparatus. The $S s$ were reminded to say the name of each picture each time it came on, and testing began. As in Experiment $I$, each picture was in each window the same number of times, but over the seven trials no $S$ saw the same picture more than once. The start of each sequence was $\mathrm{S}$ activated. The
CONTROLLED REHEARSAL

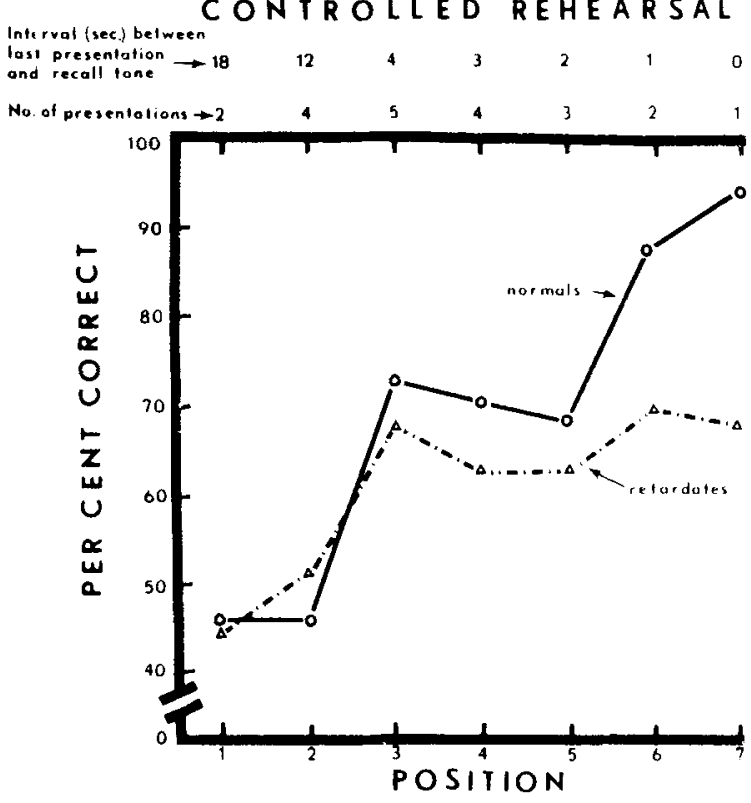

Fig. 5. Temporal curves of retarded and equat-MA normal groups, Experiment II. Number of repetitions and elapsed time are presented along the top abscissa.

Ss had little difficulty in naming a slide in the $1 \mathrm{sec}$ it was illuminated.

\section{Results}

First, since in both experiments the preliminary identification task was the same for all Ss, the free-recall scores of the 28 normals and 28 retardates were compared. Of the 49 pictures, normals recalled an average of 11.75 , while the retarded group recalled an average of 11.64 , a difference which is not statistically significant. In addition, both groups produced almost identical U-shaped serial position curves with surprisingly robust primacy effects. These results must be viewed cautiously, of course, since the order of presentation in this preliminary task was the same for all Ss. Nevertheless, in view of the fact that Ss had not been told that recall would be requested but were instructed merely to name the pictures as they came on, these results are congruent with those of Fagan and Avdeef (1973) in showing a clear primacy effect for incidental learning, despite the fact that our list was six times as long. We can conclude from the equality of performance of the two $\mathrm{S}$ groups in the preliminary task, as well as in Experiment I, that their free-recall capacity under unimpeded conditions was the same, as was their distribution of recall. For this reason, group differences in Experiment II (see below) take on added weight.

The results for the controlled rehearsal experiment are shown in Fig. 5. The bow-shaped curve is no longer evident. The curve approximates a step function (more precisely, a two-step function for the retarded group and a three-step function for the normal group). The ANOVA indicated a significant groups effect $[F(1,156)$ 


\section{CONTROLLED REHEARSAL}

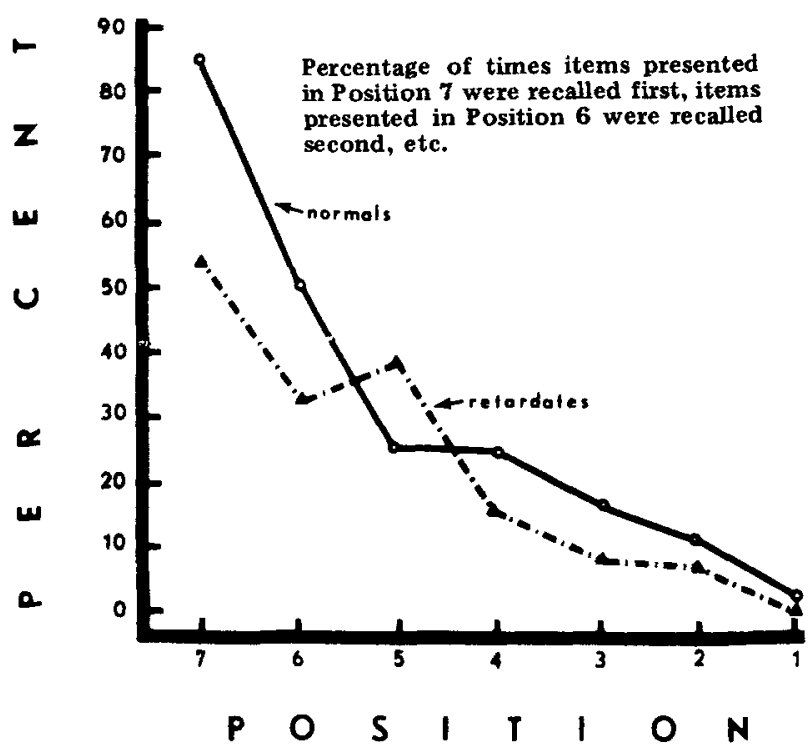

Fig. 6. Order of recall for the recency items, Experiment II.

$=5.60, \mathrm{p}<.05]$, a significant serial position effect $[\mathrm{F}(6,156)=20.71, \mathrm{p}<.001]$, and a significant interaction $[\mathrm{F}(6,156)=2.71, \mathrm{p}<.05]$.

The normal group recalled an average of 4.89 pictures per set, significantly more than the average of 4.35 recalled by the retarded group $[\mathrm{t}(26)=2.46, \mathrm{p}<.05]$ and significantly more than the average recall $(4.49)$ of the normals in Experiment I $[t(26)=2.16, p<.05]$. The scores of the retarded groups in the two experiments did not differ reliably from each other.

The primary source of the difference between the retarded and normal groups in Experiment II was the

CONTROLLED REHEARSAL

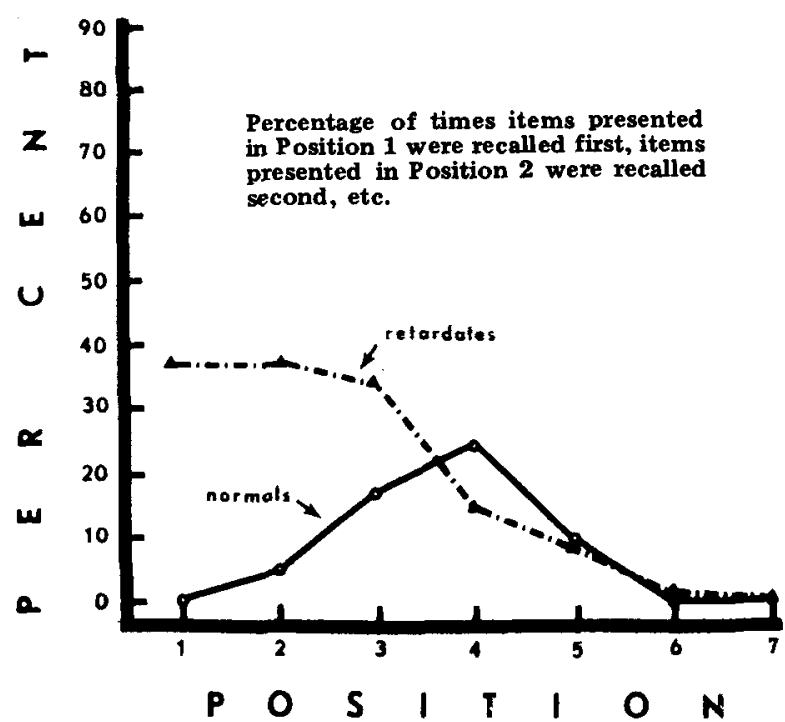

Fig. 7. Order of recall for the primacy items, Experiment II. superior performance of the normals on Position 7 $[\mathrm{t}(26)=3.66, \mathrm{p}<.002]$ and Position $6[\mathrm{t}(26)=2.89$, $\mathrm{p}<.01]$. At no other positions were differences statistically reliable.

The reason for the normal group's superiority is apparent from the strategies of recall. As Fig. 6 shows, the normals more frequently started recall with the final item and gave the penultimate item second. Both differences are reliable $(p<.05)$. On the other hand, as Fig. 7 shows, retardates reliably $(p<.05)$ more often than normals recalled the item in Position 1 first and the item in Position 2 second. No other differences in either Fig. 6 or Fig. 7 were statistically significant. As further evidence that order of recall strategy was a major source of the retarded group's deficit, there were 14 instances in which nine retardates recalled the seventh item first and the sixth item second. Average recall of these 14 instances was 4.91, which approximates the recall (4.89) of the equal-MA group.

\section{GENERAL DISCUSSION}

The inverted J-shaped curve of serial recall may be ascribed to the imposed restriction on recall strategy. However, once this restriction is lifted, as in free recall, differential recall strategy is allowed to operate and the J-shaped curve appears (Jahnke, 1965). Consequently, in serial presentation free-recall experiments, Ss can use not only input strategies (such as rehearsal and grouping) but also output strategies (such as order of recall). In Experiment I, despite the fact that normals had a significant primacy effect and retardates did not, lack of reliable group differences at any portion of the curve or in total recall precludes any firm conclusion concerning possible differences between $\mathrm{S}$ groups in input strategy, and similar order of recall curves indicate that both groups used similar order of recall strategies. This is supported further by the equivalent recall and bow-shaped distribution produced by both groups on the free recall of the preliminary identification task.

In Experiment II the manner in which items were presented presumably eliminated any possibility of differential input strategies. Frequency of item repetition and elapsed time were controlled. However, order of recall strategy was not. The controlled input variables apparently played the primary role in creating the stepwise shape of the recall curve, but order of recall strategy was also influential and was instrumental in differentiating the two $\mathrm{S}$ groups. Why the retarded Ss used a less efficient strategy in Experiment II can only be conjectured. The order of presentation in Experiment II was fixed, and perhaps this cued some of the retarded Ss to respond more frequently in a similar fixed order, from first to last. In any case, the results are in line with other evidence that retardates differ from normals not so much in memory capacity as in the use of efficient organizing strategies (Spitz, 1966, 1973). 
Whereas this had been demonstrated previously as inefficient organization of material for storage, the present results suggest that, under certain conditions, they also use a less efficient strategy of retrieval (Butterfield, Wambold, \& Belmont, 1973).

In Experiment II, despite the restricted rehearsal of the first item-which was last presented $18 \mathrm{sec}$ prior to recall-it was recalled $45 \%$ of the time by both groups. Frequent rehearsal is not a prerequisite for input into secondary memory. By the same token, number of presentations had little differential effect. Item 2 was presented four times, and Items 3 and 4 were presented five and four times, respectively; yet Item 2 was recalled far less often than Items 3 and 4 . These results are congruent with numerous studies which show that duration in short-term storage has, by itself, little effect on an item's registration in secondary memory (Craik \& Watkins, 1973). Cumulative rehearsal can, of course, maintain an item in primary memory, as it apparently did in Experiment I. But when Ss are prevented from using an input strategy (such as selective rehearsal), order of recall plus trace decay account best for the result ing curve.

\section{REFERENCES}

Atkinson, R. C., \& Shiffrin, R. M. Human memory: A proposed system and its control processes. In $\mathrm{K}$. W. Spence and J. T. Spence (Eds.), The psychology of learning and motivation. Vol 2. New York: Academic Press, 1968.

Belmont, J. M., \& Butterfield, E. C. Learning strategies as determinants of memory deficiencies. Cognitive Psychology, $1971,2,411-420$.

Bray, N. W. Controlled forgetting in the retarded. Cognitive Psychology, 1973, 5, 288-309.

Brown, A. L., Campione, J. C., Bray, N. W., \& Wilcox, B. L. Keeping track of changing variables: Effects of rehearsal training and rehearsal prevention in normal and retarded adolescents. Journal of Experimental Psychology, 1973, 101, 123-131.
Butterfield, E. C., Wambold, C., \& Belmont, J. M. On the theory and practice of improving short-term memory. American Journal of Mental Deficiency, 1973, 77, 654-669.

Craik, F. I, M., \& Watkins, M. J. The role of rehearsal in short-term memory. Journal of Verbal Learning \& Verbal Behavior, 1973, 12, 599-607.

Ellis, N. R. Memory processes in retardates and normals. In N. R Ellis (Ed.), International review of research in mental retardation. Vol. 4. New York: Academic Press, 1970.

Fagan, J. F., III, \& Avdeef, S. T. Serial position effects in incidental free recall following semantic and nonsemantic orienting tasks. Paper presented at the meeting of the Psychonomic Society, St. Louis, November 1973.

Feigenbaum, E. A., \& Simon, H. A. A theory of the serial position effect. British Journal of Psychology, 1962, 53, 307-320.

Fischler, I., Rundus, D., \& Atkinson, R. C. Effects of overt rehearsal processes on free recall. Psychonomic Science, 1970 , $19,249-250$

Hasher, L. Position effects in free recall. American Journal of Psychology, 1973, 86, 389-397.

Jahnke, J. C. Primacy and recency effects in serial-position curves of immediate recall. Journal of Experimental Psychology, 1965, 70, 130-132.

Jensen, A. R. An empirical theory of the serial-position effect. Journal of Psychology, 1962, 53, 127-142.

Kellas, G., A sheraft, M. H., \& Johnson, N. C. R ehearsal processes in the short-term memory performance of mildly retarded adolescents. American Journal of Mental Deficiency, 1973, 77, 670-679.

Rundus, $D$, A nalysis of rehearsal processes in free recall. Journal of Experim ental Psychology, 1971, 89, 63-77.

Spitz, $H$. $H$. The role of input organization in the learning and memory of mental retardates. In N. R. Ellis (Ed.), International review of research in mental retardation. Vol. 2. New York: Academic Press, 1966.

Spitz, H. H. Consolidating facts into the schematized learning and memory system of educable retardates. In N. R. Ellis (Ed.), International review of research in mental retardation. Vol. 6. New York: Academic Press, 1973.

Waugh, N. E., \& Norman, D. A. Primary memory. Psychological Review, 1965, 72, 89-104.

Welch, G. B., \& Burnett, C. T. Is primacy a factor in association-formation. American Journal of Psychology, 1924, 35, 396-401.

(R eceived for publication May 5,1974 ; revision accepted July $4,1974$. ) 